\title{
Visualization of dominant stress-transfer mechanisms in experimental debris flows of different particle-size distribution
}

\author{
Nicoletta Sanvitale and Elisabeth T. Bowman
}

\begin{abstract}
Physical modelling of debris flow in a small-scale flume has been carried out to investigate the internal stress-transfer mechanisms within unsteady, saturated, and segregating granular free-surface flows. Measurements of the internal velocity fields within model flows were obtained via planar laser-induced fluorescence and particle image velocimetry. Normalized velocity profiles taken at a section over the flow duration were found to essentially collapse onto a single curve, the shape of which was dependent on the particle-size distribution. While all flows exhibited internal basal slip and shear, for tests on well-graded materials that are most representative of debris flows, the shear rate was found to reduce towards the surface to near-zero, exhibiting near plug-flow. Dimensional analysis shows that particles of different size within these flows experienced different dominant stress-transfer mechanisms - frictional, collisional or viscous. Rapid grain-size segregation therefore is both due to and results in different modes of stress transfer within a single flow. This means that in a segregating and hence, stratified system, different flow regimes will act concurrently at microscale and mesoscale. Results highlight the complexity of debris flows, so that it may be undesirable to ascribe a single microscale constitutive behaviour throughout, and further calls into question the concept of flow regimes for debris flows based on bulk measurements.
\end{abstract}

Key words: debris flow, dimensionless number, flow regime, plane laser-induced fluorescence, flume model tests.

Résumé : La modélisation physique de l'écoulement des débris dans un canal à petite échelle a été réalisée pour étudier les mécanismes de transfert de contraintes internes au sein des flux à surface libre granulaires instables, saturés et séparés. Les mesures des champs de vitesse internes au sein des flux modèles ont été obtenues par vélocimétrie à fluorescence induite laser plane a par Image de particule. Les profils de vitesse normalisés pris à une section sur la durée d'écoulement ont été trouvés à se replier essentiellement sur une seule courbe, dont la forme était dépendante à la distribution de la taille des particules. Alors que tous les flux ont exposé un glissement basal interne et de cisaillement, pour les essais sur des matériaux bien classés qui sont les plus représentatifs des flux de débris, le taux de cisaillement a été trouvé à se réduire vers la surface près de zéro, présentant presque un écoulement piston. L'analyse dimensionnelle montre que des particules de taille différente au sein de ces flux ont connu différents mécanismes de transfert de contrainte dominante - de frottement, collisionnel, ou visqueux. La ségrégation rapide à taille de grain est donc à la fois en raison de résultats et dans différents modes de transfert de contrainte dans un seul flux. Cela signifie que dans un système de ségrégation et donc, stratifié, les différents régimes d'écoulement agissent simultanément à l'échelle micro et méso. Les résultats mettent en évidence la complexité des flux de débris, de sorte qu'il peut être souhaitable d'attribuer un seul comportement constitutif micrométrique tout au long, et en outre remettre en cause le concept de régimes d'écoulement des débris des flux basés sur des mesures en vrac. [Traduit par la Rédaction]

Mots-clés : flux de débris, nombre sans dimension, débit, fluorescence induite par laser plane, essais sur modèle de canal.

\section{Introduction}

In nature, debris flows - high-speed gravity-driven landslides comprising soil, rock, and water (Hungr et al. 2001) - represent one of the most dangerous geophysical phenomena due to their unpredictability, high mobility, and destructive power (Iverson 1997; Jakob and Hungr 2005). The mechanics of debris flows is made complex by the large range of particle sizes within the flowing mass, from boulders to clay, which segregate during motion. Larger particles tend to focus toward the flow front while fluid concentrates in the tail, altering the behaviour in time and space (Pierson 1986; McArdell et al. 2007; Leonardi et al. 2015). At the microscale, the dynamics of such particle-fluid systems involves momentum exchange processes caused by inertial granular collisions, friction between grains, viscous shear, and solid-fluid in- teractions (Iverson 1997). Depending on the relative importance of these processes, debris flows exhibit different behaviour commonly interpreted as occurring in different flow regimes (Iverson 1997; Iverson and Denlinger 2001; Ancey 2007).

Debris flow mechanisms can be studied through field observations, large- and small-scale experiments, and numerical modelling. The advantage of observations made under real-world conditions is that scaling considerations are not necessary and the full range of behaviour may be exhibited (Genevois et al. 2000; McArdell et al. 2007; McCoy et al. 2010; Comiti et al. 2014). However, as quantitative measurements can only be made during catastrophic and unpredictable events, the possibility of gathering systematic data is limited. Furthermore, macroscale observations of flow events, even for instrumented torrents, are limited to measurements of bulk parameters (e.g., front velocity, flow depth, basal

Received 27 October 2015. Accepted 9 August 2016.

N. Sanvitale and E.T. Bowman. Department of Civil and Structural Engineering, University of Sheffield, Sir Frederick Mappin Building, Mappin St., Sheffield, S1 3JD, UK.

Corresponding author: Nicoletta Sanvitale (email: n.sanvitale@sheffield.ac.uk).

Copyright remains with the author(s) or their institution(s). This work is licensed under a Creative Commons Attribution 4.0 International License (CC BY 4.0), which permits unrestricted use, distribution, and reproduction in any medium, provided the original author(s) and source are credited. 
fluid pressure, basal normal and shear forces). Large-scale modelling has been found to be very useful in replicating, at near fullscale, the field conditions of debris flows (Major 1997; Iverson et al. 2010); however, these types of experiments are costly, and may be limited by the boundary conditions that can be applied. Numerical modelling may be undertaken at the particulate scale using, for example, the discrete element method, to understand granular flow mechanisms, such as frictional and collisional stress transfer, and particle segregation (Campbell and Brennan 1985; Silbert et al. 2001; Gray and Chugunov 2006; Rognon et al. 2007). However, this numerical modelling can be computationally expensive and such studies suffer from being restricted by one or more of the following: two-dimensional (2D) geometry, use of spherical or round rather than angular particles, limited particle numbers, no interstitial fluid, small range in particle size, restriction to steady flow, and use of periodic boundaries. For these reasons, small-scale laboratory experiments, which enable the fundamental interaction of particles to be observed and related to the constitutive behaviour, are also necessary; accepting the difficulties in scaling debris flows for physical modelling (Chau et al. 2000; Bowman and Sanvitale 2009; Sanvitale and Bowman 2012; Kaitna et al. 2014; Paleo Cageao 2014; De Haas et al. 2015).

\section{Dimensional scaling}

To produce flows that correctly reflect debris flow mechanics at laboratory scale, Iverson (1997) and Iverson and Denlinger (2001) presented the case for matching particular nondimensional numbers identified and associated with specific theoretical flow regimes (e.g., Bagnold and Savage numbers) at field scale. The Savage number, $N_{\text {Sav }}$, represents the ratio of inertial shear stress caused by grain collisions to quasi-static shear stress associated with Coulomb frictional sliding and enduring grain contacts. For debris flows it can be defined as (Iverson et al. 2010)

$$
N_{\text {Sav }}=\frac{\rho_{\mathrm{s}} \dot{\gamma}^{2} \delta^{2}}{\sigma_{\mathrm{z}}-u_{\mathrm{z}}}
$$

where $\rho_{\mathrm{s}}$ is the density of the solids, $\dot{\gamma}$ is the characteristic shear rate, $\delta$ is the characteristic grain diameter, $\sigma_{z}$ is the total normal stress at $z$, and $u_{z}$ is the fluid pressure at $z$ (note that $z$ is most often taken to be the base of the flow in bulk calculations, whereas here we vary its position for the derivation of local parameters). The Bagnold number, $N_{\text {Bag, }}$, is defined in eq. (2) by the ratio of inertial grain collisions to viscous fluid shear stresses (Iverson 1997)

$$
N_{\text {Bag }}=\frac{v_{\mathrm{s}}}{\left(1-v_{\mathrm{s}}\right)} \frac{\rho_{\mathrm{s}} \delta^{2} \dot{\gamma}}{\mu}
$$

where $v_{\mathrm{s}}$ is the volumetric solid concentration and $\mu$ is the dynamic viscosity of pore fluid with suspended sediment. In this equation, Iverson (1997) replaced the factor $\lambda^{1 / 2}=\left[v_{s}^{1 / 3} /\left(v_{*}^{1 / 3}-\right.\right.$ $\left.\left.v_{\mathrm{s}}^{1 / 3}\right)\right]^{1 / 2}$ originally used by Bagnold (1954) with $v_{\mathrm{s}}\left(1-v_{\mathrm{s}}\right)$ (where $v_{*}$ is the maximum value achievable by $v_{\mathrm{s}}$ in the flow).

Savage and Hutter (1989) found that grain collision stresses dominate grain friction stresses if $N_{\text {Sav }}$ is greater than about 0.1 and Bagnold (1954) demonstrated that in highly sheared neutrally buoyant mixtures of spherical grains and liquid, collisional stresses dominate viscous fluid stresses if $N_{\text {Bag }}$, as defined by Iverson (1997), exceeds roughly 200. Note that this value differs from Bagnold's (1954) value of 450, because Iverson (1997) replaced the factor $\lambda^{1 / 2}$ in his analysis.

The dimensionless numbers, $N_{\text {Sav }}$ and $N_{\text {Bag }}$, were originally defined for simple shearing of steady, uniform mixtures of monodisperse spherical grains (Bagnold 1954; Savage and Hutter 1989). Nonetheless, as discussed, they are commonly used to identify limiting flow regimes for debris flows (Iverson 1997; Iverson and Denlinger 2001; Iverson et al. 2004) by estimating bulk parameters from visual observations at flow margins (e.g., front or surficial velocity and height) and idealized kinematic reconstruction (e.g., shear rate and slip velocity) (Iverson 1997; Zhou and $\mathrm{Ng}$ 2010; Chen et al. 2014). Most importantly, such dimensional analyses usually take into account a single characteristic grain diameter, usually the mean diameter, $D_{50}$, to represent the solid material, while often no excess pore pressure is assumed, given the paucity of field measurements (McArdell et al. 2007; McCoy et al. 2010).

In reality, particles of different size may be expected to experience different dominance of collisional or contact stress, with particles smaller than average being more influenced by contact and viscous stresses and larger particles by collisional stresses. The segregation of particles and fluid within a well-graded flow includes regions where fine particles and fluid dominate, and regions where coarse particles predominate (as at the head of flows). Therefore, it may be more appropriate to consider evolving values of the Savage and Bagnold numbers for debris flows rather than a single bulk value (Iverson et al. 2010). Such evolving values may take into account that different momentum transport processes dominate, or several processes act jointly, in different parts of the system.

To investigate the mechanisms within the interior of such flows, we present the results of flume studies conducted using transparent debris and a nonintrusive optical technique (Sanvitale and Bowman 2012). This method combines the refractive index matching of transparent solids and fluid (Budwig 1994; Wiederseiner et al. 2010) with the use of the planar laser-induced fluorescence (PLIF) techniques so that a two-dimensional slice through the system can be viewed (Montemagno and Gray 1995; Stohr et al. 2003; Dijksman et al. 2012). The scaling principles and bulk characteristics (front velocity, deposit morphology, etc.) of a suite of experiments, designed to capture aspects of granular debris flow behaviour using well-graded and uniform materials, was previously presented in Sanvitale and Bowman (2012). Here for these same experiments, we present analyses of the interior velocity fields at a section of the channel, as well as depth-averaged and local shearing behaviour over time. Using dimensional analysis, this enables the dominant stresstransfer mechanisms to be assessed from both bulk-derived values, as most commonly used, and from locally derived values, returning to the original particle-scale approach from which flow regime concepts were derived.

\section{Experimental procedure}

The experimental set up, described in detail in Sanvitale and Bowman (2012), is briefly given here. Tests were conducted in a small-scale flume (Fig. 1). A curved chute guided the mixture from the mouth of the tank to the straight portion of the slope, at which point it travelled down the $150 \mathrm{~mm}$ wide by $2 \mathrm{~m}$ long channel before being deposited on a horizontal runout surface. The glass bottom of the straight slope was artificially roughened over a length of $1 \mathrm{~m}$ with a slip resistant material. A $\sim 2 \mathrm{~mm}$ slit in the material let a $1.5 \mathrm{~mm}$ thick $532 \mathrm{~nm}$ laser light sheet pass through the bottom to illuminate the flowing material at a distance of $35 \mathrm{~mm}$ from the transparent sidewall. A high-speed camera located close to the end of the flume recorded images of the illuminated cross section at 1100 frames per second with a resolution of $1280 \times 256$ pixels. A long pass filter was placed over the lens to transmit only the fluorescence signal. The flume was set with a slope at $24.5^{\circ}$, typical of a debris flow transition reach (Fannin and Wise 2001).

For the experiments, a mixture of Duran glass particles and a hydrocarbon fluid, produced by Cargille Laboratories to match the refractive index of the glass (Table 1), was used. Particles smaller than $4 \mathrm{~mm}$ were angular as a result of being produced by crushing glass tubes, whereas the coarser grains were sub 
Fig. 1. Apparatus employed in the test: (a) schematic layout of PLIF system; (b) set up of the experiment. [Colour online.]

(a)

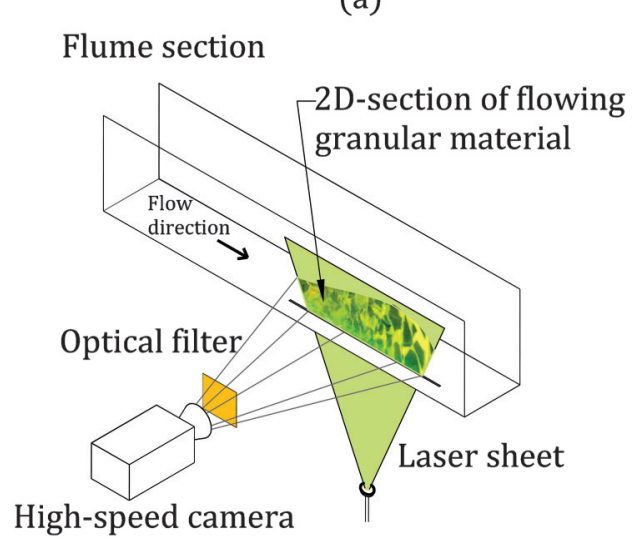

Table 1. Solid and fluid properties.

\begin{tabular}{lllll}
\hline & & $\begin{array}{l}\text { Refractive } \\
\text { index at }\end{array}$ & $\begin{array}{l}\text { Kinematic } \\
\text { viscosity at }\end{array}$ & $\begin{array}{l}\text { Density } \\
\text { at } 25^{\circ} \mathrm{C}\end{array}$ \\
Pairing & Material & $589.3 \mathrm{~nm}$ & $25^{\circ} \mathrm{C}\left(\mathrm{m}^{2} / \mathrm{s}\right)$ & $\left(\mathrm{g} / \mathrm{cm}^{3}\right)$ \\
\hline \multirow{2}{*}{ Artificial } & Hydrocarbon oil & $1.4715\left(\right.$ at $\left.25^{\circ} \mathrm{C}\right)$ & $16 \mathrm{E}^{-6}$ & 0.846 \\
\multirow{2}{*}{ Field } & Duran glass & $1.4718\left(\right.$ at $\left.21^{\circ} \mathrm{C}\right)$ & - & 2.23 \\
& Soil & - & - & 2.65 \\
& Water in debris flow & $1.3333\left(\right.$ at $\left.20^{\circ} \mathrm{C}\right)$ & $1-10 \mathrm{E}^{-6}$ & 1.00 \\
\hline
\end{tabular}

rounded particles produced by cutting and subsequently shaping small pieces of glass obtained from rods of different diameter. Besides being optically compatible, the properties of the adopted solid and fluid closely matched those of real debris flow materials, including the ratio of densities; however, the fluid viscosity was greater than that of water (see Table 1). To replicate the development and dissipation of nonhydrostatic pore pressure with the increased fluid viscosity, the glass particles were accordingly scaled-up four times with respect to a prototype grain-size distribution used in previous research on similar chute flow experiments (Bowman and Sanvitale 2009), resulting in a similar hydraulic conductivity (Sanvitale and Bowman 2012).

For all experiments, a mixture was prepared with $12 \mathrm{~kg}$ particles saturated with the fluid in which a fluorescent dye, necessary for the application of PLIF, was dissolved, producing an average sediment volume concentration $v_{s}=0.57$ (i.e., porosity $n=0.43$ ). The PLIF technique relies on the use of the thin laser sheet to activate the fluorescence of the dye diluted in the fluid, and here created an illuminated plane inside the flow in which particles appeared as dark shapes against a bright background.

Three particle-size distributions (PSDs) were used (Fig. 2) to examine the influence of a change in the coefficient of uniformity, $C_{\mathrm{U}}=D_{60} / D_{10}$, around a particular mean particle size, $D_{50}=7.1 \mathrm{~mm}$, where $D_{x}$ denotes the percentage passing by mass. Materials termed "PSD9" and "PSD11" were well-graded, with $C_{\mathrm{U}}=20.2$ (denoted to one significant figure, " $C_{\mathrm{U}}=20$ ") and 9.8 (" $C_{\mathrm{U}}=10$ "), respectively, whereas "PSD16" was more uniform with $C_{\mathrm{U}}=3.3$ (" $C_{U}=3$ "). For each grading, two experiments were carried out to ensure repeatability. Table 2 summarizes the main parameters for the tests.

\section{Velocity measurements}

The internal velocity field of the granular flows was estimated via Particle Image Velocimetry, using GeoPIV software (White et al. 2003). For a soil problem undergoing deformation, GeoPIV calculates the displacement field within a plane via a series of images taken over the course of deformation. It does this by tracking the image texture (i.e., the spatial variation of brightness) of (b)

Fig. 2. Particle-size distributions (PSDs) for solid materials used in the tests and in a typical field event (Yakadake deposits (Takahashi 1991)). [Colour online.]

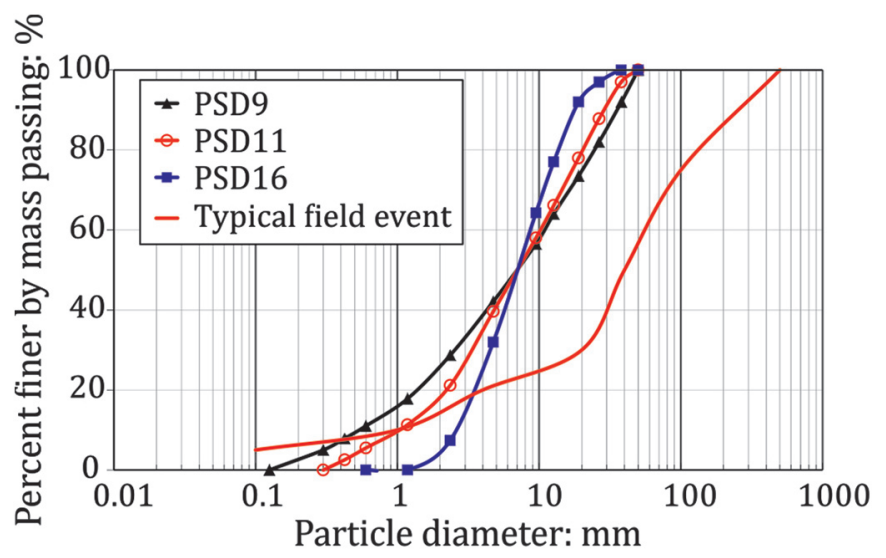

Table 2. Experimental conditions and results.

\begin{tabular}{|c|c|c|c|c|c|c|}
\hline Test & $C_{\mathrm{U}}$ & $\begin{array}{l}D_{90} \\
(\mathrm{~mm})\end{array}$ & $\begin{array}{l}D_{50} \\
(\mathrm{~mm})\end{array}$ & $\begin{array}{l}D_{10} \\
(\mathrm{~mm})\end{array}$ & $\begin{array}{l}\text { Front } \\
\text { velocity } \\
(\mathrm{m} / \mathrm{s})\end{array}$ & $\begin{array}{l}\text { Runou } \\
\text { (m) }\end{array}$ \\
\hline PSD9a & 20.2 & 35.5 & 7.1 & 0.54 & 2.48 & 0.94 \\
\hline PSD9b & 20.2 & 35.5 & 7.1 & 0.54 & 2.31 & 0.85 \\
\hline PSD11a & 9.8 & 28.7 & 7.1 & 1.1 & 2.04 & 0.70 \\
\hline PSD11b & 9.8 & 28.7 & 7.1 & 1.1 & 2.05 & 0.71 \\
\hline PSD16a & 3.3 & 17.6 & 7.1 & 2.7 & 1.49 & 0.60 \\
\hline PSD16b & 3.3 & 17.6 & 7.1 & 2.7 & 1.52 & 0.60 \\
\hline
\end{tabular}

subregions or "patches" of the original image in subsequent frames. The original version of GeoPIV was modified to the needs of the present work by supporting a static mesh of interrogation patches with position and geometry fixed in all images, rather than tracking one patch over the course of several images (Bryant et al. 2015). In the analysis, the granular flow moves through the patches. The mesh used was composed of a single column of square patches overlapping in the slope-normal direction (Fig. 3) up to the free surface of the flow. Two meshes with patch sizes of 32 and 16 pixels were used with spacing of 8 and 4 pixels, respectively. Patch size influences the precision of the measurements (White et al. 2003). Small patches allow a higher spatial resolution to be obtained, and hence more detailed, although more noisy, results. Larger patches produce less scatter and improved precision, but at the expense of resolution. Average velocity profiles were obtained by first calculating instantaneous velocities at sub- 
Fig. 3. Example of a GeoPIV 32pix mesh overlapping the flow. [Colour online.]

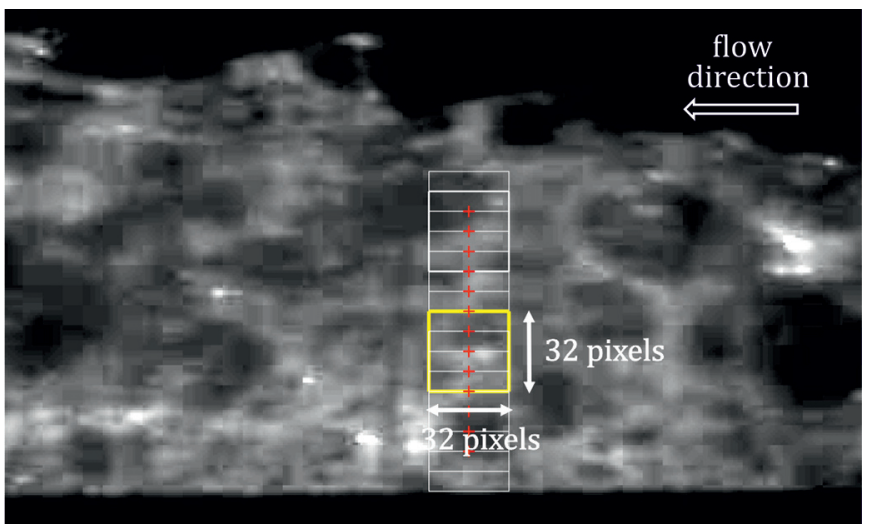

sequent time steps (i.e., two subsequent frames) over 30 successive frames (corresponding to a time interval of $0.027 \mathrm{~s}$ ) and then averaging them. To filter the outliers, a trimmed mean was calculated by discarding the values falling outside a proper confidence interval. For analyses using patches of 32 pixels (hereafter called 32pix), the confidence interval was set to two standard deviations, while for those using patches of 16 pixels (hereafter called 16pix), the confidence interval was set to one standard deviation to reduce the scatter associated with the correspondingly noisier data. A 2D Cartesian coordinate system was adopted in which the $x$-axis points down the flume (slope-parallel) and the $y$-axis is orthogonal upward (slope-normal). Figure 4 shows an example of the distribution of the $x$ and $y$ velocity components, obtained using both patch sizes, with velocities located at the centre of the corresponding patch (note that the maximum height of the flow, $h_{\max }$, is given by the height of the top patch of the mesh and therefore is approximately 4 and $2 \mathrm{~mm}$ smaller than the true height for the 32 pix and 16pix mesh, respectively). The error bars show the standard deviation that represents the dispersion around the estimated velocity averages; these were found to be (as a percentage) $20 \% \pm 9 \%$ and $14 \% \pm 5 \%$ for 16 pix and 32 pix, respectively. The $y$ velocity component was found to be at least one order of magnitude smaller than that of the $x$-direction and therefore its contribution was neglected in the following analyses.

\section{Results}

\section{Depth-averaged behaviour}

The PIV analysis starts from the part of the flow immediately behind the front, as the unsaturated condition at the beginning of the surge prevents use of the PLIF technique. The time $t=0$ is the instant at which the front position arrives at a distance of $25 \mathrm{~cm}$ before the exit to the deposition area.

The evolution of the depth-averaged velocity (Fig. 5) is estimated using the 16pix mesh to allow the investigation of the thinner parts of the flow at the tail of the surge. The mean velocities are found to be higher for larger $C_{\mathrm{U}}$, tending to decrease (with fluctuations) from the head to the tail, and the runout length is also greatest for larger $C_{\mathrm{U}}$ (Table 2), correlating to the front velocity. This agrees with previous research (Takahashi 1980; Hungr et al. 1984) that found that the front velocity of a debris flow at the point at which it exits from a confined reach to an unconfined area or fan is relatively well correlated to the runout distance. See Sanvitale and Bowman (2012) for detailed runout observations for the tests.

\section{Internal velocity profiles}

Parts $(a)$ and $(b)$ in Figs. 6-8 show the evolution with time of the mean velocity profiles estimated with the 32pix mesh. Note that the depth of the flow is an approximation of the true height due to
Fig. 4. Example of distribution of the $x$ (horizontal) and $y$ (vertical) components of the velocity obtained at each patch using both mesh sizes for test PSD16a.

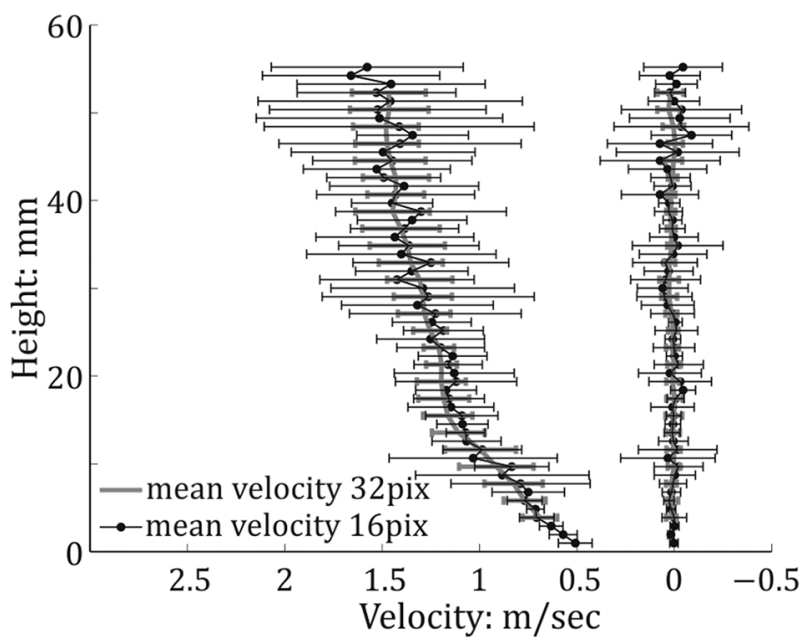

a restriction imposed by the software, which fails if the patch closest to the top of the flow falls in the completely dark region outside the free surface (i.e., where average pixel intensity is zero).

For all tests, the velocity profiles show a convex shape and slip velocities at the base. The experiments with uniform material exhibit profiles converging in a narrow range of velocity values at all the considered time steps, whereas the well-graded mixtures show a larger decrease of the velocities with time, the profiles being distributed over a broader interval. Note that PSD16a $\left(C_{\mathrm{U}}=3\right)$ has a singular behaviour, in that it is the only test in which there is an increase of the mean velocity after the arrival of the flow front as can be seen in Fig. 6a. In addition, it does not appear to slow down like PSD16b, in which the velocity decreases slightly. Such behaviour can be appreciated even by a visual inspection of the video recorded by the high-speed camera. As no problems were detected during the test, it is possible that a temporary interlocking of particles occurred at the head of the flow, slowing down the surge head and causing the rest of the material to back up behind, although it is not possible to be certain.

Figures $6 c, 7 c$, and $8 c$ show the normalized velocity profiles, i.e., the flow height normalized by the flow depth, $h_{\max }$, against the velocities scaled by the depth-averaged velocity $\bar{v}=\sum^{N} v_{i} \mathrm{~d} h / h_{\max }$, where $N$ is the number of the patches in the mesh and $\mathrm{d} h$ is the height of the patch. Using the scaled profiles, any variation in the normalized velocity can be seen as distinct from the overall bulk motion and from the variations of the flow depth. For example, the peculiarity of test PSD16a is highlighted in Fig. $6 c$, such that the experimental points of PSD16b settle on a curve with a gradually reducing slope, while the shape of the PSD16a distribution steepens in the upper part. In Fig. $7 c$, the normalized data of both test runs of PSD11 $\left(C_{\mathrm{U}}=\right.$ 10) show a similar behaviour with a nearly constant increase of the velocity with the height slightly decreasing at the top. This behaviour is even more pronounced for the tests with $C_{\mathrm{U}}=20$ (i.e., PSD9) with profiles that are convex below $y / h_{\max } \approx 0.6$, but showing nearly constant velocities for the upper part (Fig. $8 c$ ).

It is interesting to compare these results with those found in other test arrangements. Armanini et al. (2005) provided velocity profiles of the granular motions of steady uniform flows of polyvinyl chloride (PVC) pellets suspended in water using a Voronoi imaging technique at the sidewall of a recirculating flume. For different slope angle and concentration they observed four regimes: immature, mature, plug, and solid bed flow. Our velocity profiles resemble the convex profiles of their observed solid bed flows with maximum shear rate at the base. Kaitna et al. (2014) 
Fig. 5. Time evolution of depth-averaged velocity estimated with 16pix mesh for all tests.

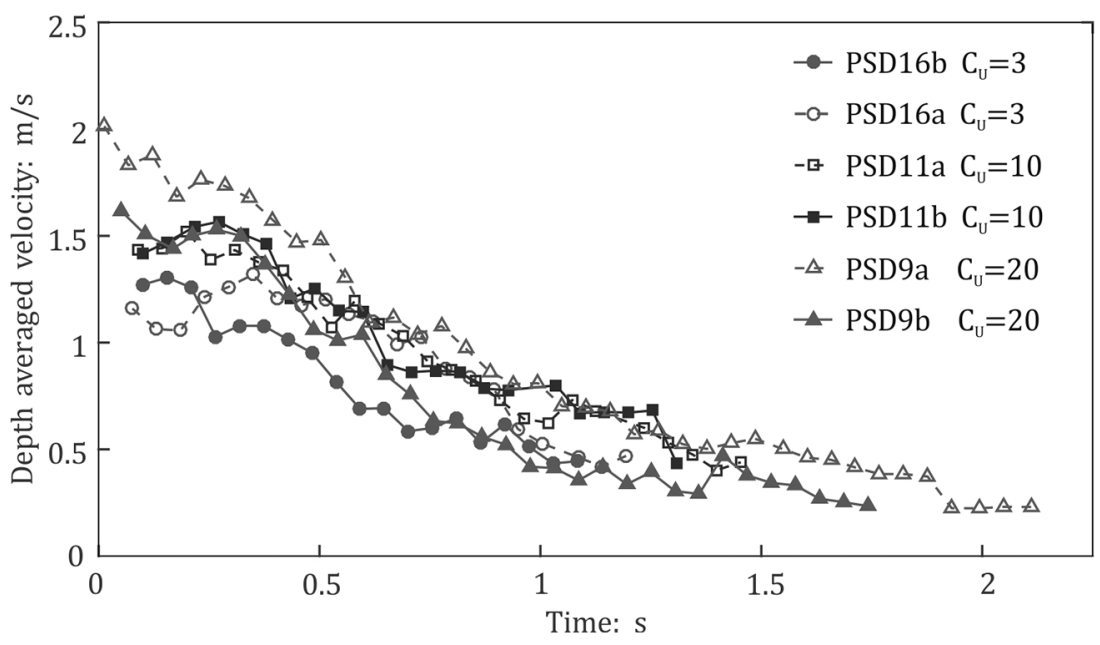

tested a range of soil-water mixtures from uniform gravel to wellgraded material in a $4 \mathrm{~m}$ diameter rotating drum. They presented the internal velocity distributions of the steady debris flows produced, with results that are qualitatively similar to our findings. For different mean velocity they found that the velocity profiles collapsed to distinct nondimensional curves for each investigated mixture, with shape varying with material composition. The mixture with the widest PSD displayed a convex profile with the greatest shearing close to the bottom and virtually no shear in the upper half of the profile.

\section{Analysis and discussion}

\section{Internal shear behaviour}

Due to the difficulties in observing the internal structure of field-scale debris flows, often in their analysis a simple shear model is hypothesized with no slip at the bed and with the velocity profile increasing linearly to a maximum at the surface. The nominal shear rate, $\Gamma$, is then calculated as the ratio of the free surface velocity, assumed to be equal to the velocity of the front, divided by the height of the flow (Phillips and Davies 1991; Iverson 1997; Zhou and Ng 2010). According to Phillips and Davies (1991), this assumption implies that shear rates are usually not larger than $10 \mathrm{~s}^{-1}$. However, both natural and experimental debris flows are also commonly assumed to have a highly sheared layer close to the bottom and an unsheared region ("plug flow") above it (Johnson 1970; Genevois et al. 2000; Parsons et al. 2001), which would result in a nonlinear shear model. Here we examine the behaviour internal to the flow so that the two viewpoints can be reconciled.

One run from each test material was selected for analysis. Figure 9 shows for all "b" runs the evolution of the nominal shear rate, $\Gamma$, and the depth-averaged shear rate, $\dot{\gamma}_{\mathrm{a}}$, which are defined in eqs. (3a) and (3b) as

$$
\begin{aligned}
& \Gamma=v_{\mathrm{s}} / h_{\max } \\
& \dot{\gamma}_{\mathrm{a}}=\left(v_{\mathrm{s}}-v_{\text {slip }}\right) / h_{\text {max }}
\end{aligned}
$$

where $v_{\mathrm{s}}$ is the surface velocity, $v_{\text {slip }}$ the slip velocity, and $h_{\max }$ the height of the flow estimated with 16pix mesh. Note that these parameters are restricted by the following approximations: the height of the flow is assumed to be the distance between the centres of the patches at the bottom and the top of the PIV mesh, hence the slip and the surface velocities are estimated at these points, respectively; the calculation was carried out excluding the part of the flows whose height is less than three patches (i.e., excluding the flow tail end) to ensure a reliable estimate of the velocity field.

During the tests, the depth-averaged shear rate was found to be rather constant, with similar mean values for all PSDs, namely $29 \mathrm{~s}^{-1}$ for the tests with $C_{\mathrm{U}}=3,31 \mathrm{~s}^{-1}$ for tests with $C_{\mathrm{U}}=10$, and $29 \mathrm{~s}^{-1}$ for those with $C_{\mathrm{U}}=20$, comparable to the results obtained in other small-scale flume experiments (Iverson and Vallance 2001). However, as discussed above, the local value of the shear rate $\dot{\gamma}(y)=\frac{\partial v(y)}{\partial y}$ can vary significantly through the depth of the flow as can be inferred from the normalized velocity profiles in Fig. 10a, which compares the velocity behaviour in the b tests for $C_{\mathrm{U}}=3$ and $\mathrm{C}_{\mathrm{U}}=20$ (the $C_{\mathrm{U}}=10$ test is omitted for clarity). In Fig. $10 \mathrm{~b}$ the normalized local shear rate, defined in eq. (4) as

$$
\frac{\dot{\gamma}}{\dot{\gamma}_{\mathrm{a}}}=\frac{\partial v(y)}{\partial y} \frac{H}{\left(v_{\mathrm{s}}-v_{\text {slip }}\right)}
$$

is presented together with the resulting fit - i.e., $\dot{\gamma} / \dot{\gamma}_{\mathrm{a}}=0.73$ $\left(y / h_{\text {max }}\right)^{-0.48}$ for the $C_{\mathrm{U}}=3$ mixture; $\dot{\gamma} / \dot{\gamma}_{\mathrm{a}}=-1.80\left(y / \mathrm{h}_{\max }\right)^{0.81}+$ 1.55 for the $C_{\mathrm{U}}=20$ mixture. The shear rate is not constant through the depth, both tests showing the highest values at the base of the flow, decreasing rapidly with height. While the $C_{\mathrm{U}}=$ 3 test, at a normalized height of about 0.4 , exhibits an approximately constant nonzero shear rate up to the top, the $C_{\mathrm{U}}=20$ test shows a decreasing shear rate, reaching values of around zero at a normalized height of 0.6 up to the free surface, corresponding to the region of zero velocity gradient as shown in Fig. $8 c$.

Similar behaviour has been observed in 2D numerical studies of dry flows down a rough inclined plane using bidisperse and quasimonodisperse assemblies of frictional cohesionless disks (Rognon et al. 2007). The authors found that the presence of large grains decreased the shear rate in the upper part of the flows, favouring sliding at the bottom, and that the thickness of the nonshearing part increased when the proportion of large grains inside the assembly was larger.

Theoretical velocity or shear profiles of debris flows have generally been derived from observations taken at flume margins in experimental flows that use uniform or near-uniform PSDs. In general, a condition of no slip has been determined for a rough base with the profile then being a function of type of soil (e.g., granular or clay dominated). Figure 11 presents the normalized interior velocity profiles (from Fig. 10) against the best fit of the interior of these flows assuming granular scaling $v(y) \propto H^{3 / 2}-$ $(H-y)^{3 / 2}$ (Bagnold 1954; Takahashi 1991), and viscous scaling in the sheared region $v(y) \propto H^{2}-(H-y)^{2}$ (Yano and Daido 1965; Johnson 
Fig. 6. Velocity profiles: time evolution of mean velocity using 32pix mesh for (a) PSD16a, (b) PSD16b, and (c) PSD16 normalized velocity profiles.

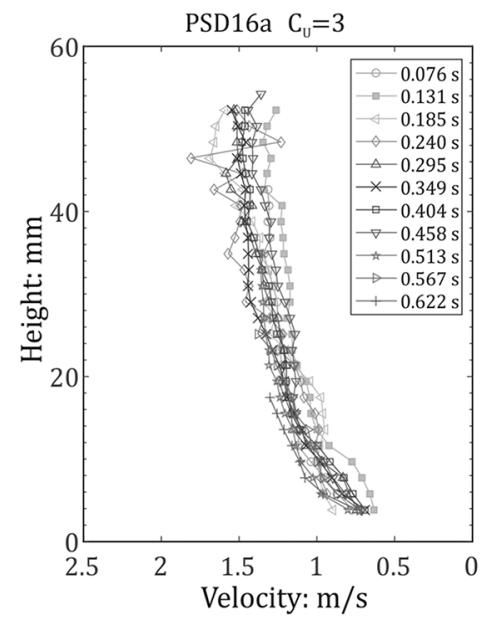

(a)

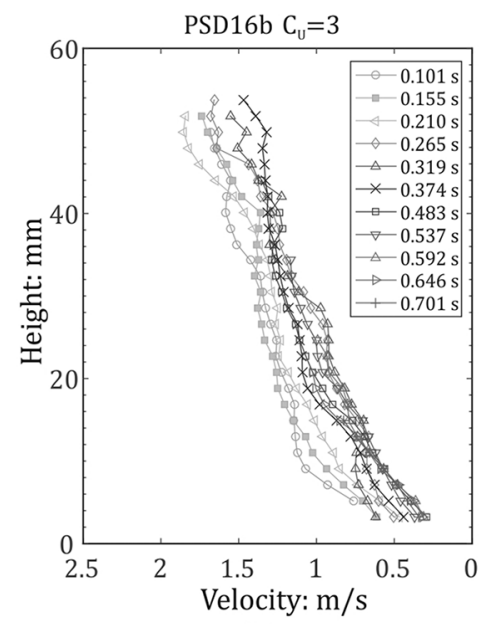

(b)

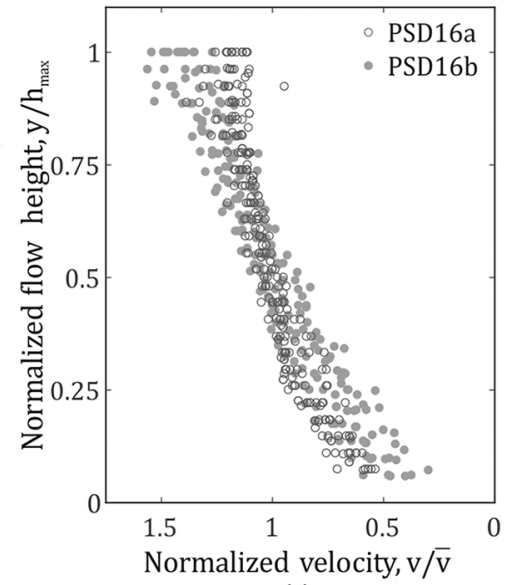

(c)

Fig. 7. Velocity profiles: time evolution of mean velocity using 32pix mesh for (a) PSD11a, (b) PSD11b, and (c) PSD11 normalized velocity profiles.

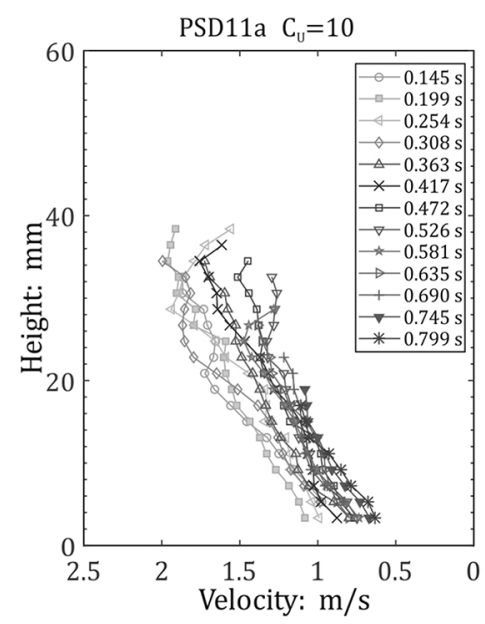

(a)

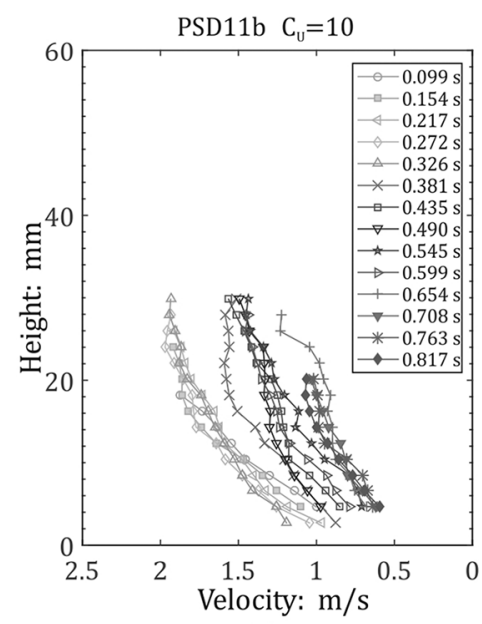

(b)

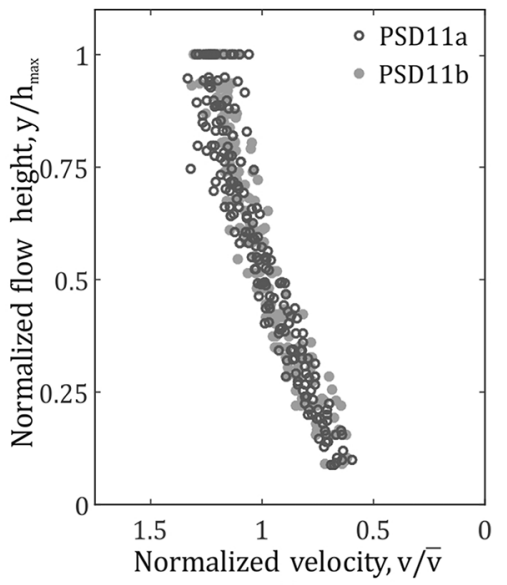

(c)

Fig. 8. Velocity profiles: time evolution of mean velocity using 32pix mesh for (a) PSD9a, (b) PSD9b, and (c) PSD9 normalized velocity profiles.

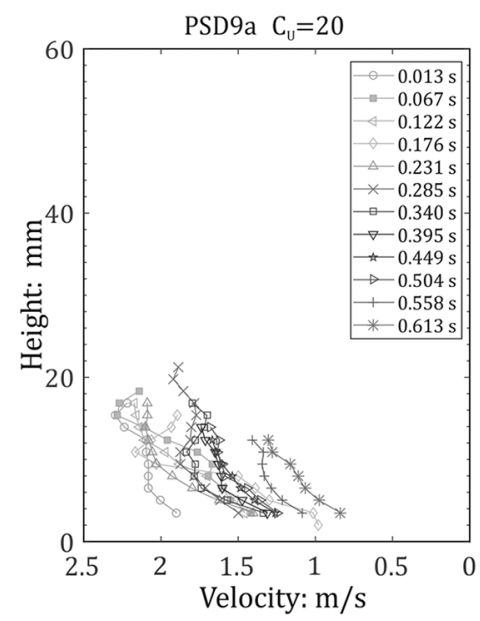

(a)

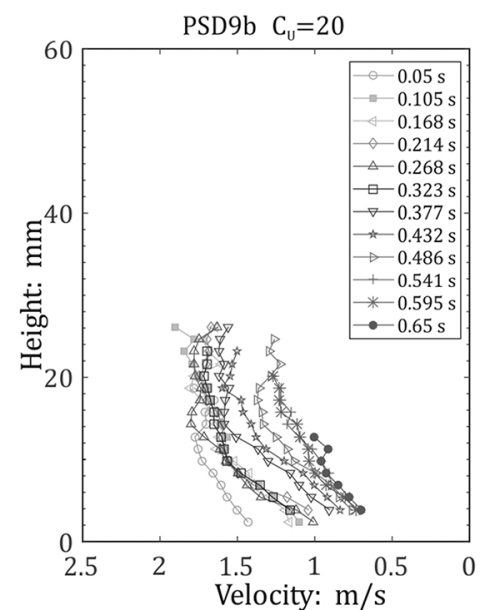

(b)

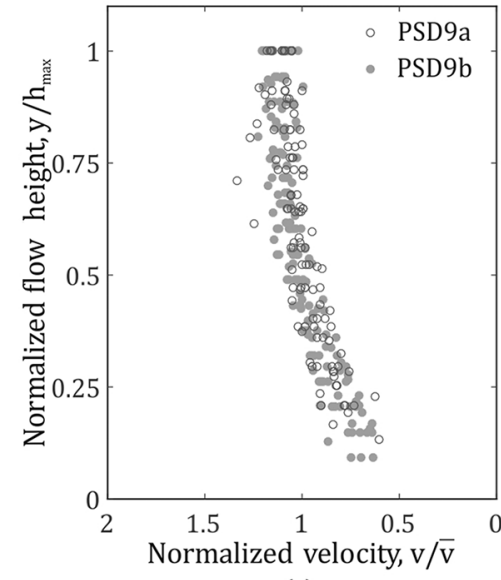

(c)

- Published by NRC Research Press 
Fig. 9. Time evolution of flow height, depth-averaged, and nominal shear rate estimated with 16pix mesh for (a) PSD16, (b) PSD11, and (c) PSD9.
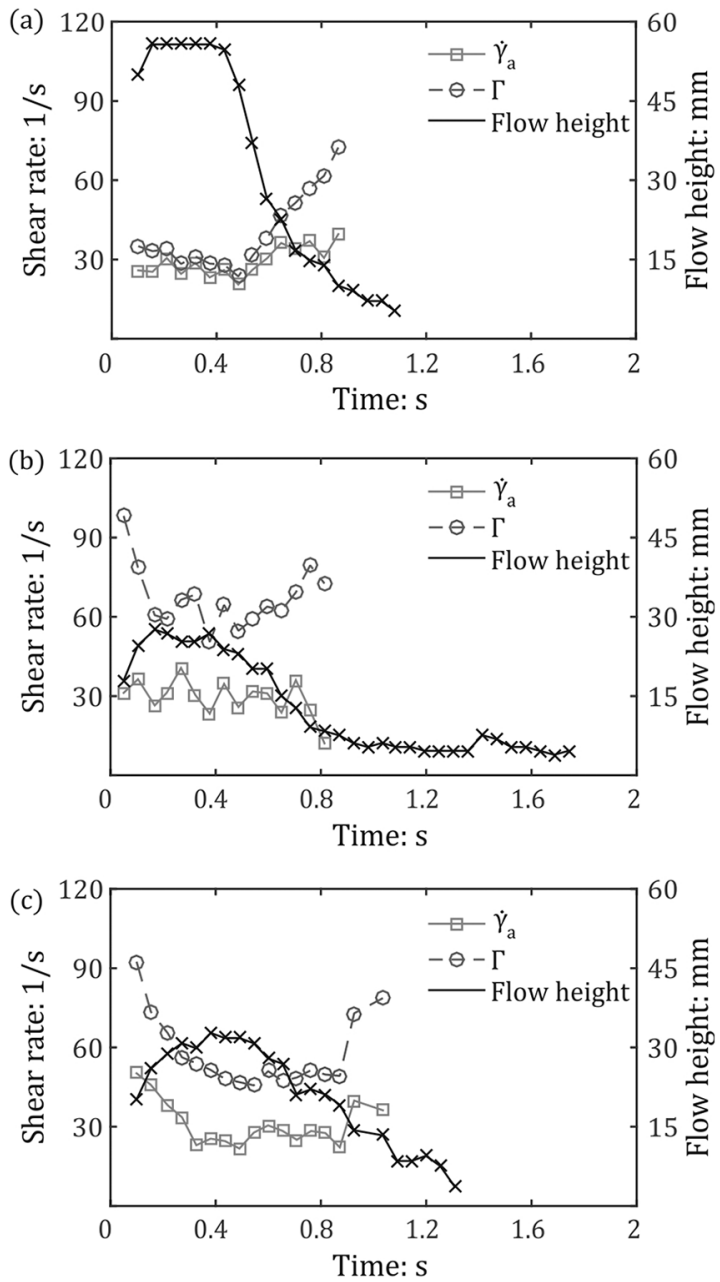

1970), modified with respect to these original forms because we assumed as boundary conditions at $y=0, v_{\text {slip }}=0.36 \mathrm{~m} / \mathrm{s}$ and $v_{\text {slip }}=$ 0.55 for $C_{\mathrm{U}}=3$ and $C_{\mathrm{U}}=20$, respectively. For the $C_{\mathrm{U}}=3$ test the best fit is provided by the granular scaling, in particular at the top of the flow where the viscous fit is not able to reproduce satisfactorily the behaviour of the mixture. In contrast, the viscous scaling results match better the behaviour of the test along the overall height of the flow for the test $C_{\mathrm{U}}=20$. The results suggest that basal slip is significant within the interior of debris flows and that results derived from interactions near the wall may not adequately represent this behaviour.

\section{Dimensionless numbers and flow regimes}

\section{Flow regimes from internal depth-averaged shear rate}

To demonstrate how different particle sizes may experience different dominant stress transfer mechanisms, we can estimate $N_{\text {Bag }}$ and $N_{\text {Sav }}$ throughout the flow considering the value of the depth-averaged shear rate resulting from the PIV analyses and assuming different characteristic grain diameters. This enables a direct comparison with data reported elsewhere (Iverson 1997; Iverson et al. 2010; Zhou and Ng 2010; Kaitna et al. 2014). Here, we choose three sizes: $D_{90}$, which may be considered as representative of the largest particles in the flow that focus to the front and create the greatest damage on impact; $D_{50}$, the mean diameter as usually used in such analyses; and $D_{10}$, which dominates mixture permeability and hence, mobility via pore pressure generation.
Note here, fluid viscosity is taken to be the actual viscosity of the fluid without the addition of fine particles, although according to Iverson (1997), its magnitude can be increased by the presence of fine material.

The basal normal stress has been calculated assuming a constant value of the solid concentration during the test so that the bulk density could be calculated as eq. (5)

$$
\rho=\rho_{\mathrm{s}}(1-n)+\rho_{\mathrm{f}} n
$$

For these experiments, basal total normal stress, $\sigma_{\text {base }}$, and fluid pressure, $u_{\text {base }}$, were not measured. Kaitna et al. (2014) obtained, from experimental flows in a rotating drum, a ratio $u_{\text {base }} / \sigma_{\text {base }}$ of around 0.4 for gravel and water mixture, up to 0.6 when the fines were present, and a value $\sim 0.9$ for muddy mixtures having wide PSD. Using large flume tests, Iverson et al. (2010) measured (after the flow front passage) values of $u_{\text {base }} / \sigma_{\text {base }} \sim 0.6$ for sand and gravel mixtures and $u_{\text {base }} / \sigma_{\text {base }} \sim 1$ for sand-gravel-mud mixtures. Given these results, for our uniform mixture with $C_{\mathrm{U}}=3$, a ratio of $u_{\text {base }} / \sigma_{\text {base }} \sim 0.6$ can be adopted, whereas for the PSD with $C_{\mathrm{U}}=20$, near full liquefaction may occur over much of the flow (i.e., $u_{\text {basel }}$ $\sigma_{\text {base }} \sim 0.9-1.0$, particularly in the tail). Therefore, in our calculation, for all mixtures the same value of $u_{y} / \sigma_{y} \sim 0.6$ (assuming a linear stress and pore pressure profile with depth $y$ ) has been used. Consequently, $N_{\text {Sav }}$ values for tests using these materials likely represent a lower bound, considering that when complete liquefaction occurs due to the presence of high pore pressures, $N_{\text {Sav }}$ becomes infinite as the stresses due to enduring grain contacts vanish entirely. This is indicated in Fig. 12 by an arrow.

Figure 12 presents the evolving values of $N_{\text {Sav }}$ and $N_{\text {Bag }}$ for the $\mathrm{b}$ tests with $C_{\mathrm{U}}=3$ and $C_{\mathrm{U}}=20$. For the most uniform mixture, it is possible to differentiate between the estimates of $N_{\text {Sav }}$ belonging to the front of the flow (where the flow depth is larger than $35 \mathrm{~mm}$ ) and those lying in the tail, the latter showing larger values. For the largest particles, $D_{90}$, the inertial grain collisions dominate the grain contact stress; at $D_{50}$ the flow is still collisional but less so $\left(N_{\text {Sav }}>0.1\right.$ and $\left.N_{\text {Bag }}>200\right)$, and by $D_{10}$, a large part of the stress is likely to be transmitted by friction $\left(N_{\text {Sav }}<0.1\right.$ and $N_{\text {Bag }}<200$ ) but viscous stresses start to be relevant.

For the most well-graded mixture $\left(C_{\mathrm{U}}=20\right)$, Fig. 12 indicates that grain collisions are expected to transmit most of the stress between $D_{90}$ and $D_{50}$, although for the smaller particles the influence of both friction and viscosity increases while $N_{\text {Sav }}$ and $N_{\text {Bag }}$ reduce, so that by $D_{10}$ viscosity becomes significant relative to both collisional and frictional stresses $\left(N_{\text {Sav }}<0.1\right.$ and $\left.N_{\text {Bag }}<20\right)$. However, it should be noted that while the analysis has assumed $u_{y} / \sigma_{y} \sim 0.6$ throughout, in fact a large portion of the flow can be reasonably assumed to be near-liquefied; hence, $N_{\text {Sav }}$ may diverge towards infinity.

Using depth-averaged values as calculated above, $N_{\text {Sav }}$ and $N_{\text {Bag }}$ are found to be larger than those ascribed to natural debris flows (Iverson 1997; Zhou and Ng 2010), and obtained using the United States Geological Survey (USGS) large experimental flume (Iverson et al. 2010) and in the large rotating drum (Kaitna et al. 2014). This is due to the shallow flow depth and high velocity, resulting in a high value of shear rate, and also to the relatively large value of the ratio of the grain size to flow depth. However, Iverson et al. (2010) also calculated two values of Savage number assuming two values of the characteristic grain size for their mixtures (sandgravel-mud). They found that generally $N_{\text {Sav }}>10$ for the gravel fraction and $N_{\text {Sav }}<0.1$ for the sand fraction, suggesting that collisional stresses were more important than grain-contact stresses for larger particles and the reverse was true for the smaller ones. Our results are in broad agreement with this, although in the next section we go further, by incorporating the local shearing behaviour of the different flows into the calculation. 
Fig. 10. (a) Comparison of normalized velocity profiles estimated with 32pix mesh for tests PSD9b and PSD16b; (b) normalized shear rate for the same tests.

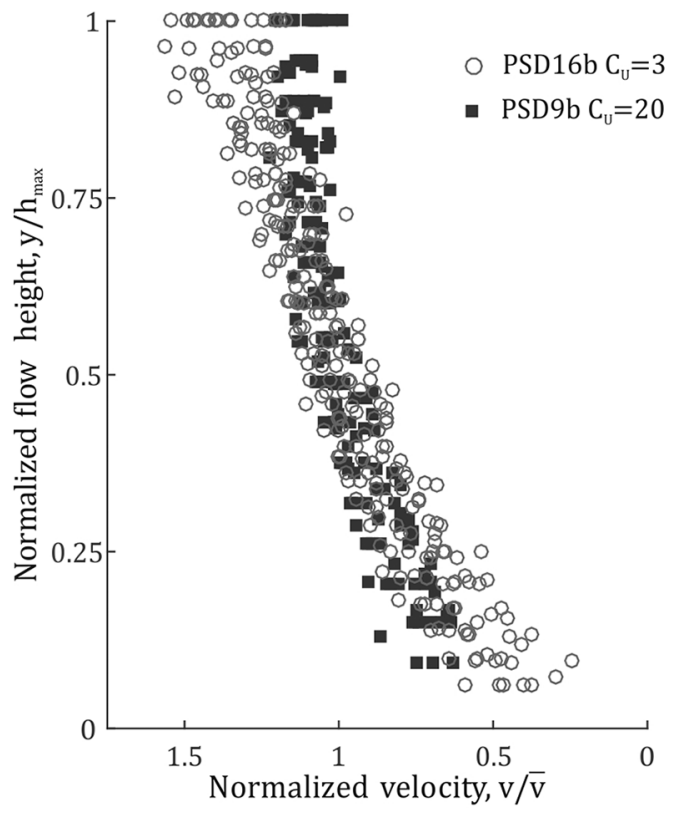

(a)
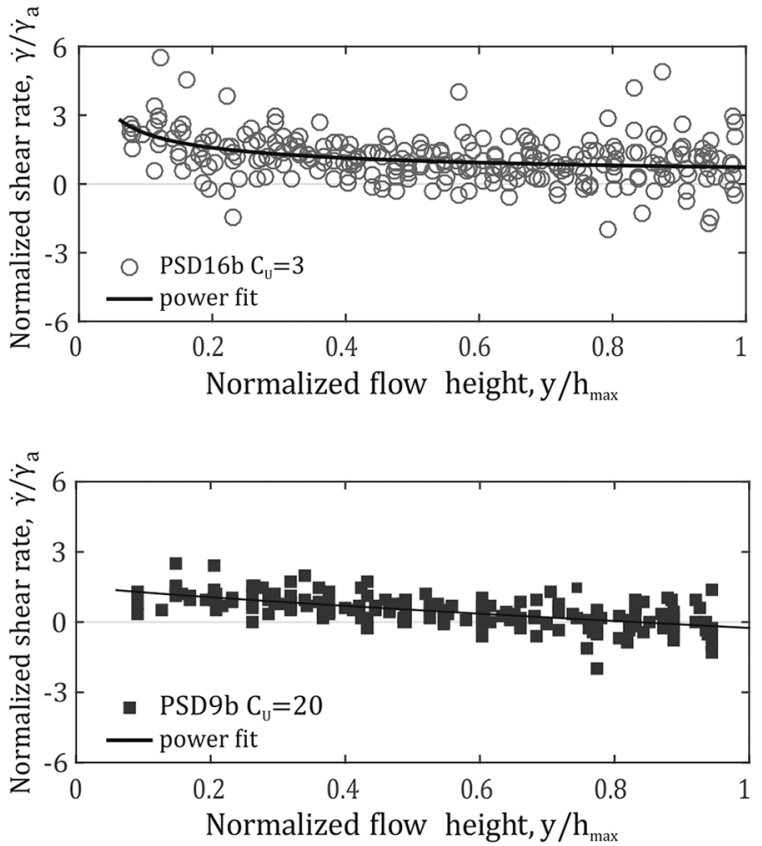

(b)

Fig. 11. Normalized velocity profiles estimated with 32pix mesh for $(a)$ test PSD16b and $(b)$ test PSD9b. Solid line shows the best fit of a granular and a viscous scaling.

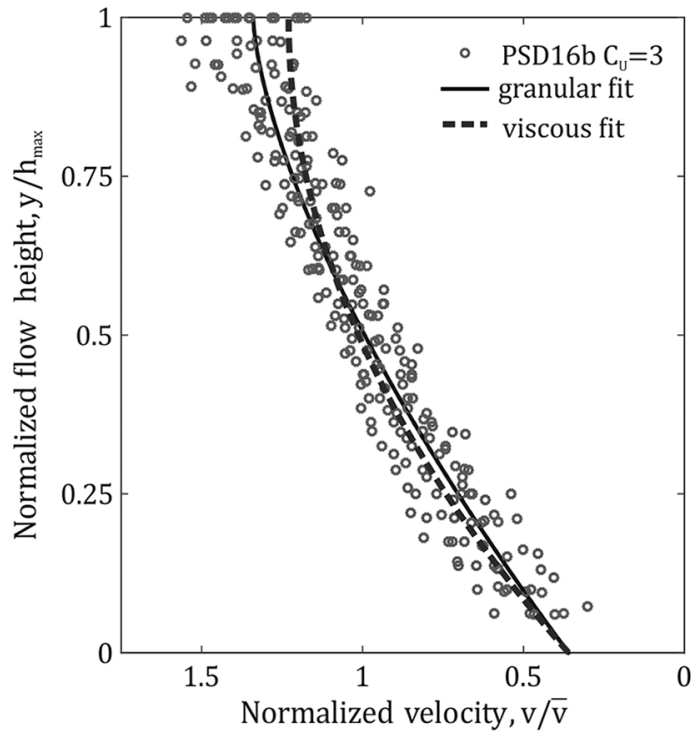

Flow regimes from internal local shear rate

Estimates in Fig. 12 experience the limitation that a linear shear model is used through the flow depth, which was not found in our experiments (Fig. 10). By determining the local shear rate with depth, we can take full advantage of the results internal to the flow and estimate accordant local values for $N_{\text {Sav }}$ and $N_{\text {Bag. }}$. Figure $13 a$ shows velocity profiles for all $b$ tests at the leading edge of the flows and a best-fit curve of the experimental velocity data obtained with the 16pix mesh. The best adaptations for the experimental velocity profile were given by the following equations: $v=$ $0.11 y^{0.62}+0.2\left(C_{\mathrm{U}}=3\right) ; v=0.76 y^{0.28}\left(C_{\mathrm{U}}=10\right) ; v=1.27 \tanh (0.15 y)+0.4$ $\left(C_{\mathrm{U}}=20\right)$. For Fig. $13 \mathrm{~b}$ we consider normalized shear rate profiles calculated using the best-fit curves. Using these local values of

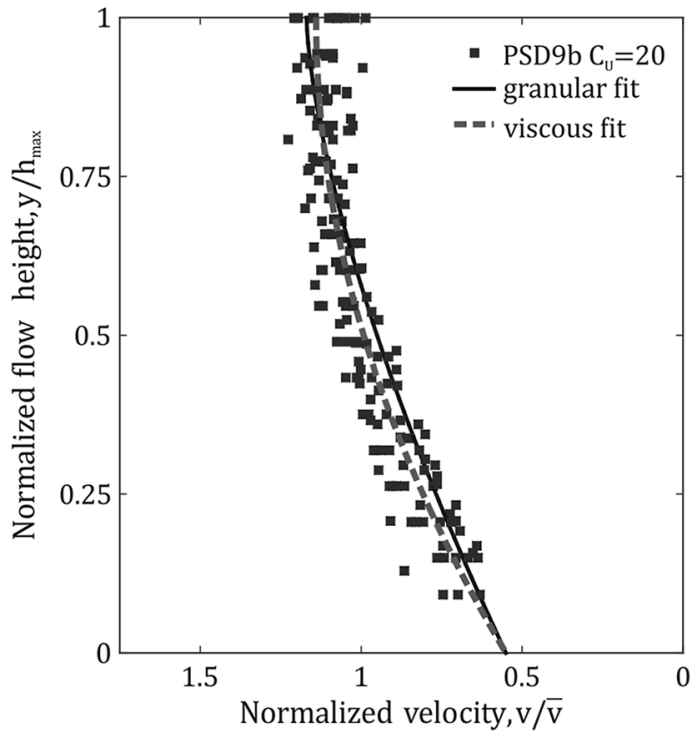

shear rate and considering a linear distribution of effective stress and pore pressure inside the flows, it is possible to estimate the variation of $N_{\text {Sav }}$ and $N_{\text {Bag }}$ through the depth.

As already shown in Fig. 10, the profile of shear rate in the tests with different PSD is significantly different and this is reflected in the resulting values of $N_{\text {Sav }}$ (Fig. 14). Figures $14 a$ and $14 b$ show that for $C_{\mathrm{U}}=3$ and $C_{\mathrm{U}}=10, N_{\mathrm{Sav}}$ calculated for each characteristic particle diameter is rather constant through the depth except at the top and bottom where $N_{\text {Sav }}$ increases. This is due to the fact that towards the free surface the effective stress is decreasing and, in the lower part of the flow, the shear rate increases. For the same flows in Figs. $15 a$ and 15b, $N_{\text {Bag }}$ values indicate inertial behaviour for all but the smallest particle sizes, varying by approximately an 
Fig. 12. Savage number against Bagnold number for the b tests with $C_{\mathrm{U}}=3$ and $C_{\mathrm{U}}=20$.

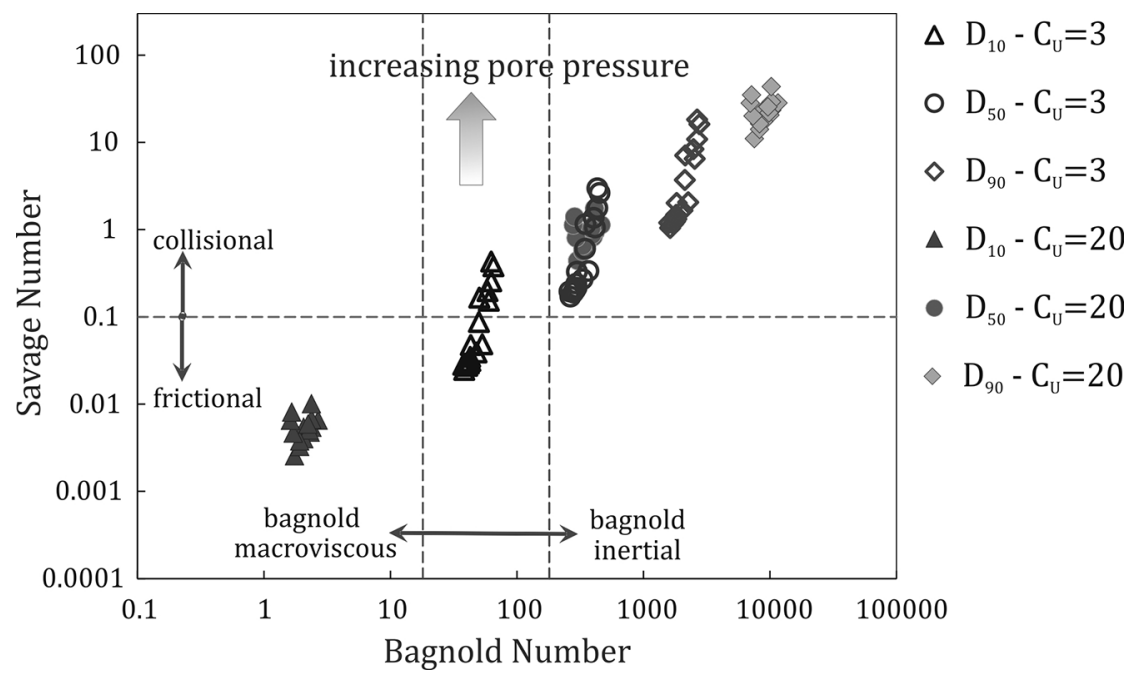

Fig. 13. (a) Example of velocity profiles estimated at leading edge of the flow. Solid lines are calculated using the best fit of the data $(v=f(y))$. (b) Normalized shear rate obtained using the corresponding fits.

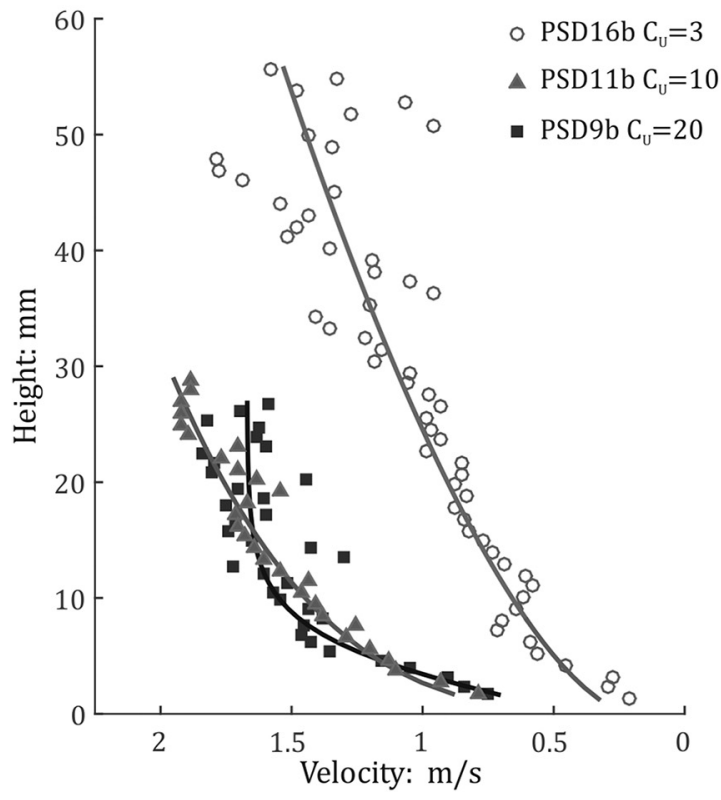

(a)

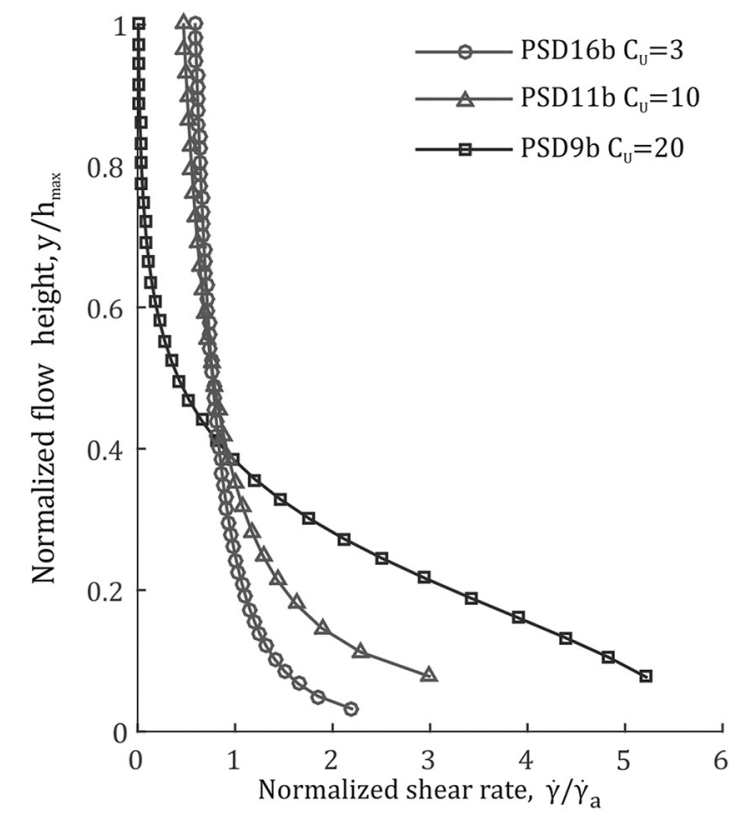

(b) order of magnitude from top to bottom. Nonetheless, for $C_{\mathrm{U}}=3$, the local values through the depth turn out to be quite close to that estimated using the depth-averaged shear rate and so the same conclusions as to the stresses acting upon particles of different sizes can be drawn for more-or-less uniform flows.

In contrast, the most well-graded flow with $C_{\mathrm{U}}=20$ (Fig. 14c) shows large differences in the values of $N_{\text {Sav }}$ through the flow depth - across four orders of magnitude for each particle size which can lead to a stratified structure characterized by either frictional or collisional behaviour. For the $D_{50}$ particle size, $N_{\text {Sav }}$ encompasses values representative of grain collisional dominance between the bottom and middle of the flow, and lower values, typical of frictional dominance, in the upper part. The same occurs for the $D_{10}$ particle size for which viscous stress transfer is found to be dominant at the top of the flow (Fig. 15c), while frictional stress becomes relevant at depth. For the largest particles, represented by $D_{90}$, grain collision stresses are found to be the dominant stress transfer mechanism through the whole depth.

\section{Conclusions}

Small-scale flume experiments were conducted to analyse the complex internal behaviour of unsteady experimental debris flows, ranging from uniform $\left(C_{\mathrm{U}}=3\right)$ to well-graded $\left(C_{\mathrm{U}}=20\right)$ mixtures of transparent debris. A nonintrusive optical approach, combining PLIF, refractive index matching, and PIV, allowed the capture of two-dimensional velocity profiles inside the granular flows, away from the influence of sidewalls. In general, for the same initial moisture content or solid concentration, the most well-graded flows developed the shallowest flows and the highest velocities. Depth-averaged velocities were found to decrease with flow duration, most particularly for well-graded mixtures, while scaled velocity profiles were found to generally collapse onto a single curve for each PSD. High shear rates (leading to large slip velocities) were found toward the flow bottom for all tests, with those of the most well-graded material producing the largest slip velocity and a near-zero velocity gradient (i.e., plug-type flow) in 
Fig. 14. Local values of $N_{\text {Sav }}$ at leading edge of the flows: (a) $C_{U}=3,(b) C_{U}=10$, and (c) $C_{\mathrm{U}}=20$.

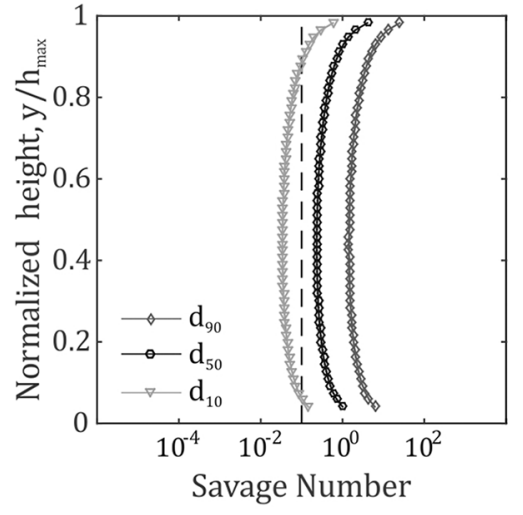

(a)

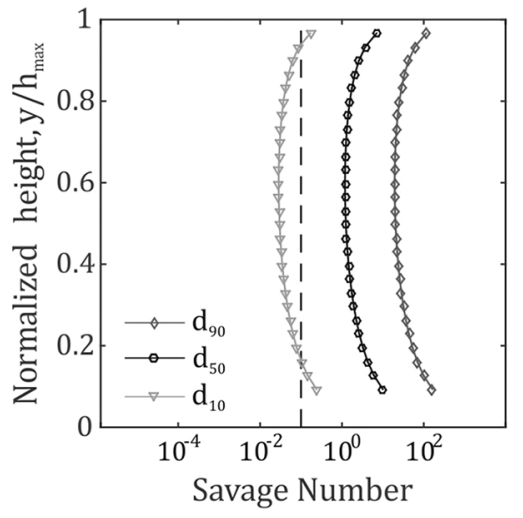

(b)

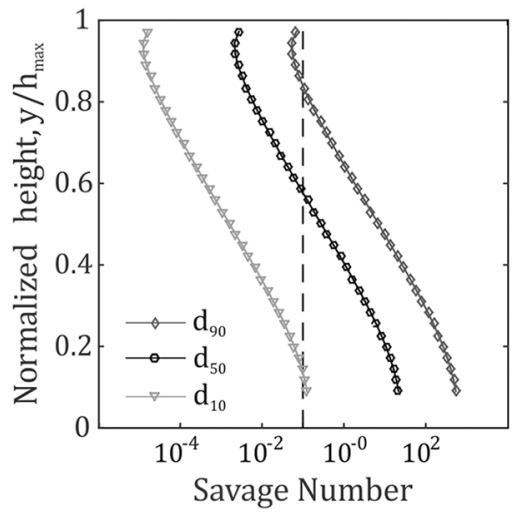

(c)

Fig. 15. Local values of $N_{\text {Bag }}$ at leading edge of the flows: $(a) C_{\mathrm{U}}=3,(b) C_{\mathrm{U}}=10$, and $(c) C_{\mathrm{U}}=20$.

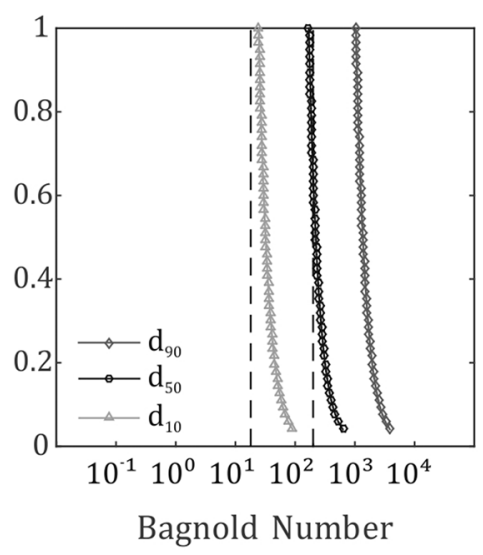

(a)

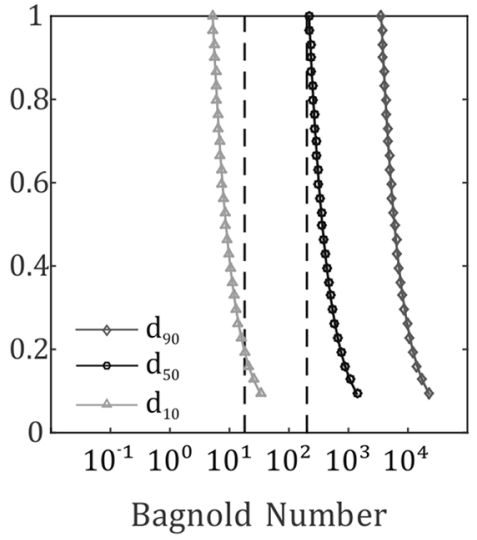

(b)

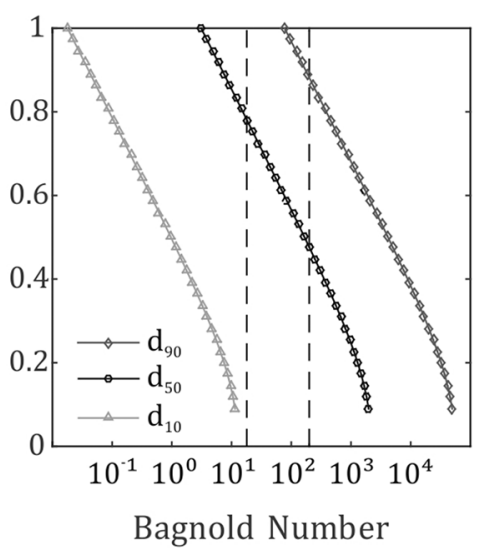

(c) the upper part. Conversely, the uniform mixture exhibited a more constant shear rate through the depth.

Dimensional analysis was conducted to assess the dominant stress transfer mechanisms acting upon particles of different sizes. We estimated the Savage and Bagnold numbers, which, according to Iverson's scaling approach, can be used to identify limiting flow regimes for debris flows. As $N_{\text {Sav }}$ and $N_{\text {Bag }}$ are both dependent on a particular characteristic particle size, we examined three different grain sizes: $D_{90}$, representing the largest particles in the flow; $D_{50}$, the mean diameter; and $D_{10}$, which governs mixture permeability and hence, mobility via pore pressure generation. $N_{\text {Sav }}$ depends also on the shear rate. For both natural and experimental debris flows, the shear rate is generally estimated assuming a linear velocity profile with depth. Following this approach, which may be applied to opaque flows, the results show that even for the uniform mixture, for which the particle sizes encompass just one order of magnitude, different stress-transfer mechanisms are found to act dependent on the particle size. From this analysis, the largest particles represented by $D_{90}$ are found to be influenced by inertial grain collisions stress; the grains at the $D_{50}$ particle size are affected by collisional stresses, although the relevance of enduring grain contacts is increasing; and by $D_{10}$ most of the stress is likely to be transmitted by frictional contact. The most well-graded mixture exhibited greater differences in regime for different particle sizes. Grain collisions were found to transmit most of the stress, even at $D_{50}$, although for the smaller particles the influence of viscosity became significant relative to both collisional and frictional stresses.
Taking full advantage of being able to view the flow internally, we further examined leading edge velocity and shear rate profiles for each PSD considering local values through the depth. Using this approach, for the more uniform mixtures the values of $N_{\text {Sav }}$ were determined to be rather constant throughout the depth, close to the values estimated using the depth-averaged shear rate. Conversely, large variations were observed within the most wellgraded flow, for which $N_{\text {Sav }}$ values were found to span over four orders of magnitude. These results show the vertical structure of well-graded granular flows, such as debris flows, to be stratified in distinct layers in which the relevance of different dominant stress for each particle size can vary along the depth.

These experimental findings highlight the complex nature of debris flows. Specifically, we see that flow behaviour and accordant flow regimes determined from bulk values may differ greatly from those locally and internally determined, putting into question some divisions that have been ascribed to debris flow regimes based on bulk observations. Further exploration of their internal mechanics at a local scale is needed to expand the fundamental understanding of the processes involved and in particular, to elucidate the role of pore pressure within such well-graded flows.

\section{Acknowledgements}

The experimental work was funded by the Marsden Fund of the Royal Society of New Zealand at the University of Canterbury, New Zealand, under the grant "The Internal Mechanics of Debris Flows". The authors were further supported by the Engineering and Physical Sciences Research Council (EPSRC), UK, under the grant award 
EP/M017427/1 "High speed granular debris flows: new paradigms and interactions in geomechanics". Data supporting this publication can be freely downloaded from the University of Sheffield Research Data Repository at http://dx.doi.org/10.15131/shef.data. 3860721, under the terms of the Creative Commons Attribution (CC-BY) license.

\section{References}

Ancey, C. 2007. Plasticity and geophysical flows: a review. Journal of NonNewtonian Fluid Mechanics, 142: 4-35. doi:10.1016/j.jnnfm.2006.05.005.

Armanini, A., Capart, H., Fraccarollo, L., and Larcher, M. 2005. Rheological stratification in experimental free-surface flows of granular-liquid mixtures. Journal of Fluid Mechanics, 532: 269-319. doi:10.1017/S0022112005004283.

Bagnold, R.A. 1954. Experiments on a gravity-free dispersion of large solid spheres in a Newtonian fluid under shear. Proceedings of the Royal Society A: Mathematical and Physical Sciences, 225(1160): 49-63. doi:10.1098/rspa.1954. 0186.

Bowman, E.T., and Sanvitale, N. 2009. The role of particle size in the flow behaviour of saturated granular materials. In Proceedings of the 17th International Conference on Soil Mechanics \& Geotechnical Engineering. Edited by M. Hamza et al. Alexandria, Egypt. pp. 470-473.

Bryant, S.K., Take, W.A., and Bowman, E.T. 2015. Observations of grain-scale interactions and simulation of dry granular flows in a large-scale flume. Canadian Geotechnical Journal, 52(5): 638-655. doi:10.1139/cgj-2013-0425.

Budwig, R. 1994. Refractive index matching methods for liquid flow investigations. Experiments in Fluids, 17: 350-355. doi:10.1007/BF01874416.

Campbell, C.S., and Brennen, C.E. 1985. Chute flows of granular material: some computer simulations. Journal of Applied Mechanics, 52: 172-178. doi:10.1115/ 1.3168990 .

Chau, K.T., Chan, L.C.P., Luk, S.T., and Wai, W.H. 2000. Shape of deposition fan and runout distance of debris-flow: effects of granular and water contents. In Proceedings of the 2nd International Conference on Debris-flow Hazards Mitigation: Mechanics Prediction and Assessment, Taipei, Taiwan. Edited by G. Wieczorek and N.D. Naeser. A.A. Balkema. pp. 387-395.

Chen, H.X., Zhang, L.M., and Zhang, S. 2014. Evolution of debris flow properties and physical interactions in debris-flow mixtures in the Wenchuan earthquake zone. Engineering Geology, 182: 136-147. doi:10.1016/j.enggeo.2014.08. 004

Comiti, F., Marchi, L., Macconi, P., Arattano, M., Bertoldi, G., Borga, M., Brardinoni, F., Cavalli, M., D’Agostino, V., et al. 2014. A new monitoring station for debris flows in the European Alps: first observations in the Gadria basin. Natural Hazards, 73: 1175-1198. doi:10.1007/s11069-014-1088-5.

De, Haas, T., Braat, L., Leuven, J.R., Lokhorst, I.R., and Kleinhans, M.G. 2015. Effects of debris flow composition on runout, depositional mechanisms, and deposit morphology in laboratory experiments. Journal of Geophysical Research: Earth Surface, 120(9): 1949-1972. doi:10.1002/2015JF003525.

Dijksman, J.A., Rietz, F., Lorincz, K.A., van Hecke, M., and Losert, W. 2012. Refractive index matched scanning of dense granular materials. Review of Scientific Instruments, 83: 011301. doi:10.1063/1.3674173. PMID:22299922.

Fannin, R.J., and Wise, M.P. 2001. An empirical-statistical model for debris flow travel distance. Canadian Geotechnical Journal, 38(5): 982-994. doi:10.1139/ t01-030.

Genevois, R., Tecca, P.R., Berti, M., and Simoni, A. 2000. Debris flow in the Dolomites: experimental data from a monitoring system. In Proceedings of the Second International Conference on Debris-flow Hazard Mitigation: Mechanics, Prediction, and Assessment, Taipei, Taiwan. Edited by G. Wieczorek and N. Naeser. A.A. Balkema. pp. 283-291.

Gray, J.M.N.T., and Chugunov, V.A. 2006. Particle-size segregation and diffusive remixing in shallow granular avalanches. Journal of Fluid Mechanics, 569: 365-398. doi:10.1017/S0022112006002977.

Hungr, O., Morgan, G.C., and Kellerhals, R. 1984. Quantitative analysis of debris torrent hazards for design of remedial measures. Canadian Geotechnical Journal, 21(4): 663-677. doi:10.1139/t84-073.

Hungr, O., Evans, S.G., Bovis, M.J., and Hutchinson, J.N. 2001. A review of the classification of landslides of the flow type. Environmental \& Engineering Geoscience, 7(3): 221-238. doi:10.2113/gseegeosci.7.3.221.

Iverson, R.M. 1997. The physics of debris flows. Reviews of Geophysics, 35(3): 245-296. doi:10.1029/97RG00426.

Iverson, R.M., and Denlinger, R.P. 2001. Flow of variably fluidized granular masses across three-dimensional terrain: 1 . Coulomb mixture theory. Journal of Geophysical Research, 106(B1): 537-552. doi:10.1029/2000JB900329..

Iverson, R.M., and Vallance, J.W. 2001. New views of granular mass flows. Geology, 29(2): 115-118. doi:10.1130/0091-7613(2001)029<0115:NVOGMF>2.0.CO;2.

Iverson, R.M., Logan, M., and Denlinger, R.P. 2004. Granular avalanches across irregular three-dimensional terrain: 2. Experimental tests. Journal of Geophysical Research, 109: F01015. doi:10.1029/2003JF000084.

Iverson, R.M., Logan, M., LaHusen, R.G., and Berti, M. 2010. The perfect debris flow? Aggregated results from 28 large-scale experiments. Journal of Geophysical Research, 115: F03005. doi:10.1029/2009JF001514.

Jakob, M., and Hungr, O. 2005. Debris-flow hazards and related phenomena. Springer.
Johnson, A. 1970. Physical processes in geology. Freeman, Cooper and Co., San Francisco.

Kaitna, R., Dietrich, W.E., and Hsu, L. 2014. Surface slopes, velocity profiles and fluid pressure in coarse-grained debris flows saturated with water and mud. Journal of Fluid Mechanics, 741: 377-403. doi:10.1017/jfm.2013.675.

Leonardi, A., Cabrera, M., Wittel, F.K., Kaitna, R., Mendoza, M., Wu, W., and Herrmann, H.J. 2015. Granular-front formation in free-surface flow of concentrated suspensions. Physical Review E, 92: 052204. doi:10.1103/PhysRevE. 92.052204 .

Major, J.J. 1997. Depositional processes in large-scale debris-flow experiments. Journal of Geology, 105(3): 345-366. doi:10.1086/515930.

McArdell, B.W., Bartelt, P., and Kowalski, J. 2007. Field observations of basal forces and fluid pressure in a debris flow. Geophysical Research Letters, 34: L07406. doi:10.1029/2006GL029183.

McCoy, S.W., Kean, J.W., Coe, J.A., Staley, D.M., Wasklewicz, T.A., and Tucker, G.E. 2010. Evolution of a natural debris flow: in situ measurements of flow dynamics, video imagery, and terrestrial laser scanning. Geology, 38: 735-738. doi:10.1130/G30928.1.

Montemagno, C.D., and Gray, W.G. 1995. Photoluminescent volumetric imaging: A technique for the exploration of multiphase flow and transport in porous media. Geophysical Research Letters, 22(4): 425-428. doi:10.1029/ 94GL02697.

Paleo Cageao, P. 2014. Fluid-particle interaction in geophysical flows: debris flow. Ph.D. thesis, Department of Civil Engineering, University of Nottingham.

Parsons, J.D., Whipple, K.X., and Simoni, A. 2001. Experimental study of the grain-flow, fluid-mud transition in debris flows. The Journal of Geology, 109(4): 427-447. doi:10.1086/320798.

Phillips, C.J., and Davies, T.R.H. 1991. Determining rheological parameters of debris flow material. Geomorphology, 4: 101-110. doi:10.1016/0169-555X(91) 90022-3.

Pierson, T. 1986. Flow behavior of channelized debris flows, Mount St. Helens, Washington. In Hillslope processes. Allen \& Unwin, Boston. pp. 269-296.

Rognon, P.G., Roux, J.N., Naiim, M., and Chevoir, F. 2007. Dense flows of bidisperse assemblies of disks down an inclined plane. Physics of Fluids, 19(5): 058101. doi:10.1063/1.2722242.

Sanvitale, N., and Bowman, E.T. 2012. Internal imaging of saturated granular free-surface flows. International Journal of Physical Modelling in Geotechnics, 12(4): 129-142. doi:10.1680/ijpmg.12.00002.

Savage, S.B., and Hutter, K. 1989. The motion of a finite mass of granular material down a rough incline. Journal of Fluid Mechanics, 199: 177-215. doi:10. 1017/S0022112089000340.

Silbert, L.E., Ertaş, D., Grest, G.S., Halsey, T.C., Levine, D., and Plimpton, S.J. 2001. Granular flow down an inclined plane: Bagnold scaling and rheology. Physical Review E, 64: 051302. doi:10.1103/PhysRevE.64.051302.

Stohr, M., Roth, K., and Jahne, B. 2003. Measurement of 3D pore-scale flow in index-matched porous media. Experiments in Fluids, 35: 159-166. doi:10.1007| s00348-003-0641-x.

Takahashi, T. 1980. Debris flow on prismatic open channel. Journal of the Hydraulics Division, ASCE, HY3: 381-396.

Takahashi, T. 1991. Debris flow. IAHR Monograph Series, Balkema, Rotterdam.

White, D.J., Take, W.A., and Bolton, M.D. 2003. Soil deformation measurement using particle image velocimetry (PIV) and photogrammetry. Géotechnique, 53(7): 619-631. doi:10.1680/geot.2003.53.7.619.

Wiederseiner, S., Andreini, N., Epely-Chauvin, G., and Ancey, C. 2010. Refractiveindex and density matching in concentrated suspensions: a review. Experiments in Fluids, 50: 1183-1206. doi:10.1007/s00348-010-0996-8.

Yano, K., and Daido, A. 1965. Fundamental study on mud-flow. Bulletin of the Disaster Prevention Research Institute, Kyoto University, 14: 69-83.

Zhou, G.G.D., and Ng, C.W.W. 2010. Dimensional analysis of natural debris flows. Canadian Geotechnical Journal, 47(7): 719-729. doi:10.1139/T09-134.

\section{List of symbols}

$C_{\mathrm{U}}$ coefficient of uniformity

$D_{10}$ effective grain size

$D_{50}$ mean grain size

$D_{60}$ particle size for which $60 \%$ of the particles are finer

$D_{90}$ particle size for which $90 \%$ of the particles are finer

$H$ height of the flow

$\mathrm{dh}$ height of the patch

$h_{\max }$ height of the PIV mesh

$N$ number of patches in the mesh

$N_{\text {Bag }}$ Bagnold number

$N_{\text {Sav }}$ Savage number

$n$ porosity

$t$ time

$u_{\text {base }}$ fluid pressure

$u_{y}$ pore pressure at depth $y$

$u_{z}$ pore pressure at depth $z$

$v$ velocity obtained through PIV analyses 

$v_{\mathrm{s}}$ surface velocity
$v_{\text {slip }}$ slip velocity
$\bar{v}$ depth-averaged velocity
$y$ coordinate along the $y$-axis
$z$ coordinate along the $z$-axis
$\delta$ characteristic grain diameter
$\Gamma$ nominal shear rate
$\dot{\gamma}$ characteristic shear rate
$\dot{\gamma}_{\mathrm{a}}$ depth averaged shear rate
$\dot{\gamma}(y)$ local value of the shear rate
$\lambda^{1 / 2}$ factor used by Bagnold (1954)

$\mu$ dynamic viscosity of pore fluid

$\rho$ bulk density

$\rho_{\mathrm{f}}$ density of the fluid

$\rho_{\mathrm{s}}$ density of the solid

$v_{*}$ maximum value achievable by $v_{\mathrm{s}}$ in the flow

$v_{\mathrm{s}}$ volumetric solid concentration

$\sigma_{\text {base }}$ basal total normal stress

$\sigma_{y}$ total normal stress at depth $y$

$\sigma_{z}$ total normal stress at depth $z$ 